(2)

\title{
Neurofibromatosis type I and attention deficit hyperactivity disorder: a case study and literature review
}

This article was published in the following Dove Press journal:

Neuropsychiatric Disease and Treatment

25 March 2015

Number of times this article has been viewed

\section{Carmen Sílvia Miguel \\ Tiffany M Chaim-Avancini \\ Maria Aparecida Silva \\ Mario Rodrigues Louzã}

Adult Attention Deficit Hyperactivity Disorder Program (PRODATH), Institute of Psychiatry, University of São Paulo, São Paulo, Brazil
Correspondence: Carmen Sílvia Miguel Adult Attention Deficit Hyperactivity Disorder Program (PRODATH), Rua Dr Ovídio Pires de Campos, 785, 3rd Floor, Room II, 05403-0I0 São Paulo SP, Brazil

Tel +55 I| 266 | 697|

Fax +55 II $266 \mid 7656$

Email carmen I sil@yahoo.com.br
Background: The cognitive profile of children with neurofibromatosis type 1 (NF1) and attention deficit hyperactivity disorder (ADHD) has been well characterized, but few studies have evaluated the cognitive abilities of adults with NF1 and ADHD.

Objectives: We investigated 1) the cognitive profile of an adult patient with NF1 and inattention problems, 2) changes in his cognition after 14 months of follow-up, and 3) whether the patient exhibited comorbid NF1 and ADHD or secondary ADHD-like symptoms.

Methods: We administered neuropsychological tests of executive function, attention, verbal and visual memory, visuospatial function, and language during two evaluations separated by 14 months.

Results: We found no changes in sustained attention, language, or verbal memory. Visual memory, verbal learning, selective attention inhibitory control, and problem solving declined over time, whereas visual search, psychomotor speed, visuospatial function, and mental flexibility improved.

Conclusion: Our patient exhibited a cognitive profile characteristic of both NF1 and ADHD, leading to the hypothesis that the patient had comorbid ADHD instead of secondary ADHDlike symptoms. More studies are necessary to characterize the cognition of patients with NF1 and ADHD.

Keywords: ADHD, executive function, NF1, low-grade pontine glioma, cognition

\section{Introduction}

Neurofibromatosis type 1 (NF1), also known as von Recklinghausen disease, is a progressive neurogenetic autosomal dominant disorder with a great heterogeneity of clinical presentations that may occur beginning in early infancy. ${ }^{1,2}$ Children with NF1 have not only physical and/or skeleton deformities but also a high frequency of migraine. ${ }^{1,3}$ Moreover, clinical manifestations of NF1 affect both the patients and the lives of their parents, as mothers of children with NF1 experience more stress than other mothers. ${ }^{4}$

Approximately $80 \%$ of children with NF1 also exhibit cognitive deficits, with severe impairment in one or more cognitive functions ${ }^{5,6}$ that negatively affects their quality of life. ${ }^{7}$ In the past, these individuals were diagnosed with mental retardation, but studies show that only $4 \%$ to $8 \%$ of people with NF1 have an intelligence quotient (IQ) of less than 70, compared with $3 \%$ found in the healthy control population. ${ }^{5}$ Between $30 \%$ to $65 \%$ of children with NF1 showed learning problems such as poor performance in writing, language, reading and reading comprehension, spelling, and mathematics. ${ }^{7}$ Although a cognitive profile of NF1 has not yet been fully described in literature, there are two lines of thought in this regard. One considers visuospatial 
deficits to be the hallmark deficits in children and adults with NF1 along with attention and executive functioning deficits ${ }^{8}$ whereas the other emphasizes the presence of both language and visuospatial deficits in conjunction with attention and executive functioning deficits. ${ }^{9}$ In a consensus statement on current guidelines for the diagnosis and management of NF $1,{ }^{10}$ report that children and adults with NF1 usually exhibit low average IQ, learning problems such as reading and writing difficulties, and deficits in visuospatial function, working memory, and attention.

An increased frequency of attention deficit hyperactivity disorder (ADHD) and autistic spectrum disorders has also been observed in individuals with NF1. ${ }^{11}$ Thirty to fifty percent of children with NF1 have behavioral problems involving attention deficits, hyperactivity, and impulsivity, thus fulfilling diagnostic criteria for ADHD according to the Diagnostic and Statistical Manual of Mental Disorders (DSM-IV). ${ }^{12}$ Symptoms of ADHD include difficulty sustaining attention, distraction, forgetfulness, disorganization, fidgetiness, and impulsivity. As a consequence, impairments in daily life are common, including disturbances in family relationships, academic performance, and professional activities. ${ }^{13}$ Similar to what is observed for patients with NF1, results of neuropsychological testing for ADHD in children or adults reveal a heterogeneous profile, with individuals affected in different domains of executive functioning and attention and to different degrees. ${ }^{14}$ In a follow-up study, children with NF1 and ADHD showed greater variability in reaction time compared with children with only NF1, suggesting that this variability is due to ADHD, and children with NF1 and ADHD showed improvement of attentional symptoms after drug treatment. ${ }^{15}$ Furthermore, Mautner et $\mathrm{al}^{12}$ observed greater variability in reaction times for patients with only ADHD or NF1 and ADHD compared with patients with only NF1. Although the symptoms of ADHD can remit in adolescence or adulthood, they can also persist throughout life. Mautner et $\mathrm{al}^{12}$ found that ADHD symptoms persist into adulthood for a high percentage of patients with NF1.

One important comorbidity of both NF1 and ADHD is sleep disorders, which can exacerbate the symptoms of both disorders. ${ }^{16}$ Although sleep disorders are frequently associated with ADHD, autism spectrum disorders, and cognitive impairment, studies of sleep disorders in children with NF1 with or without ADHD have produced conflicting results. One study reports that children and adolescents with NF1 show more frequent difficulties in initiating and maintaining sleep and abnormalities in sleep-wake transitions compared with their siblings without NF $1 .{ }^{17}$ Other studies show a lower frequency of global sleep disorders in children with NF1 with or without ADHD compared with that in the general population. ${ }^{16,18}$ In another study, in which parents completed questionnaires about the sleep and behavior of their children with or without NF1, there was only a significant difference between groups in parasomnias. Furthermore, children with both NF1 and sleep disorders exhibit more conduct disorders, hyperactivity, and emotional dysregulation compared with children with only NF1. ${ }^{19}$

With only a few studies of cognition in adults with NF1, ${ }^{20}$ there is a scarce body of knowledge regarding this population. Reviewing the literature on NF1 and ADHD in adults, we found only one report of IQ and attention profiles associated with this comorbidity and no reports of the cognitive progression of both disorders. ${ }^{12}$ When there is a paucity of literature on a topic, case studies can be useful for generating new hypotheses. ${ }^{21}$ Here, we report a case of an adult with NF1, ADHD, and low-grade pontine glioma. Our objectives were to examine the cognitive profile of the patient and changes in his cognition after 1 year of follow-up. Furthermore, we sought to determine the relationship between NF1 and inattention, that is, whether the patient exhibited comorbid ADHD or secondary ADHD-like symptoms.

\section{Methods}

The procedures used in this case study were in accordance with the Helsinki Declaration of 1975 as revised in 2013. The patient gave written informed consent for the publication of this report.

\section{Case report}

M, a 28-year-old, right-handed male, was diagnosed with NF1 at the age of 10 years old. After graduating with a degree in marketing in 2007, he worked in this occupation for 6 months. After becoming unemployed, he spent his time surfing the Internet on a computer in his bedroom. His mother reported that he had a childhood history of ADHD. He was referred to our Adult Attention Deficit Hyperactivity Disorder Program (PRODATH) at the Institute of Psychiatry, University of São Paulo, São Paulo, Brazil, due to his complaints of "bad memory" and "concentration difficulty". On August 1, 2011, a psychiatrist with expertise in ADHD performed his clinical interview, which included the Structured Clinical Interview for the DSM-IV, Text Revision (DSM-IV-TR) ${ }^{22}$ and the Schedule for Affective Disorders and Schizophrenia for School-Age Children-Present and Lifetime Version (adapted module, version 6.0$)^{23}$ to confirm the diagnosis of ADHD and diagnose potential axis I comorbidities. To assess symptom severity, 
we used the Adult ADHD Self-Report Scale. ${ }^{24} \mathrm{M}$ was diagnosed with ADHD-inattentive type according to DSM-IV-TR criteria. At that time, he did not show humor symptoms or any other psychiatric comorbidity. The patient reported no sleep difficulties. Methylphenidate (immediate release [MPH-IR]) was prescribed at a dosage of $10 \mathrm{mg}$ twice daily.

Also on August 1, 2011, M underwent magnetic resonance imaging, which detected a tumor in the basilar segment of the left pons. The size of the tumor was $1.8 \times 0.9 \times 1.4 \mathrm{~cm}$ (anterior-posterior $\times$ lateral-lateral $\times$ cranial-caudal). Radiologists diagnosed a low-grade glioma based on characteristics of the images. During follow-ups on March 5 and May 3, 2012, the glioma showed stability with a size of $2 \times 1 \times 1.5 \mathrm{~cm}$ (anterior-posterior $\times$ lateral-lateral $\times$ cranialcaudal). The case was not a candidate for surgery, as the tumor region was densely vascularized. No other abnormalities in the magnetic resonance imaging were noted.

\section{First neuropsychological evaluation}

During the first clinical interview, when questions were addressed directly to $\mathrm{M}$, he answered: "I do not know!", "What do you want me to say?!", and "I can not explain." When asked about his relationships with his siblings as a child, he answered: "Cool!" In response to the question "What is 'cool' to you?", M said: "Mom, explain to her [the interviewer] what "cool' is." The mother prompted him by saying: "You enjoyed playing with ..." She reported that M is very critical and, when faced with situations in which he sees injustice, he is mobilized. He showed no interest in having a girlfriend. He reported difficulties in concluding projects that he initiated and in organizing his activities; he was not able to develop any piece of work to its completion. During childhood, he played alone, and he did not like mathematics at school because he could not understand the equations. He stated that he was an average student and never repeated a grade, which was confirmed by his mother. $\mathrm{M}$ did not attend special education programs. M's mother reported no learning problems during his childhood but she is a teacher and helped him in his schoolwork when necessary.

M completed a neuropsychological test battery consisting of the Mini-Mental State Exam (MMSE); ${ }^{25}$ Wisconsin Card Sorting Test (WCST; Odessa FL, USA); Digit Span Test, Forward and Backward (Wechsler Adult Intelligence Scale [WAIS]-III); ${ }^{26}$ Block Design Test (Wechsler Adult Intelligence Scale revised [WAIS-R]) ${ }^{27,28}$ Vocabulary Test (WAIS-R) ${ }^{27,28}$ Stroop Test ${ }^{29}$ Trail Making Test (TMT), parts A and B; ${ }^{29}$ Rey-Osterrieth Complex Figure Test (ROCF); $;{ }^{30}$ Continuous Performance Test (CPT; Multihealth Systems Inc., North
Tonawanda, NY, USA); Controlled Oral Word Association Test - COWAT (FAS Test); ${ }^{29}$ and Rey Auditory Verbal Learning Test (RAVLT) ${ }^{29}$ The Vocabulary and Block Design Tests were used to provide an estimated IQ score. These tests were chosen because they are used in the literature to measure cognitive functions in individuals with NF1 and ADHD.

M's low average IQ of 89 fell within the range indicated by a study of children and adults with NF1, and his Vocabulary and Block Design Test scores were below expected values. ${ }^{8}$ His MMSE score was in the high average range. His Block Design Test score was below expected and his ROCF score indicated severe impairment. Poor visuospatial processing is common in children and adults with NF1 and suggests an impaired ability to perceive social cues, a low level of organization, and an increase in impulsivity. ${ }^{8,31}$

After instructions were given for the attention and calculation subtests of the MMSE, M took some time before saying anything and then asked, "Do you want me to keep talking?! Is that so?!" When requested to write a sentence, he said: "A sentence?! What kind of sentence? I do not know any off-hand! ... Can I Google it?!" It took him 59 seconds to write a sentence. Also, the vocabulary subtest of the MMSE showed that M's verbal knowledge acquired through learning and his cultural background was below expected. Studies of children with NF1 reveal their difficulties in defining words, understanding simple passages in a text, and describing figures. ${ }^{5} \mathrm{M}$ showed slight deficits in phonetic verbal expression during the examination, suggesting mild inefficiency in his organization of thought and search for words. Similar observations have been made for children and adults with NF1. ${ }^{8}$

We found inefficiency in M's working memory when we analyzed Forward and Backward Digit Span Tests separately, but we failed to find impairment when we examined the Digit Span Test as a single assessment. M demonstrated impaired ability to retain and filter relevant information presented by the environment and showed difficulties in abstraction, concept formation, and changes in cognitive strategies in response to environmental demands. In the TMT part A, a simple visual sequential and concurrent task, M's execution was slow, suggesting moderate difficulty in visual search and motor speed. His sustained attention (CPT), inhibitory control (Stroop III), mental flexibility (TMT part B), verbal learning (RAVLT), verbal memory (RAVLT), and visual memory (ROCF) were preserved. In RAVLT, M apparently took advantage of repetition for the consolidation of verbal learning and memory and showed no difficulty in storing new information. 


\section{Second neuropsychological evaluation}

$\mathrm{M}$ underwent a second neuropsychological evaluation 14 months after the first evaluation. M said that he had taken $10 \mathrm{mg}$ MPH-IR twice daily for 3 weeks following the first evaluation. He had discontinued the medication on his own and continued with psychotherapy for 3 more months, with ongoing psychiatric follow-ups. He had resumed taking $10 \mathrm{mg}$ MPH-IR twice daily 2 months earlier. During the second evaluation, $\mathrm{M}$ had been in an off-medication state for over 12 hours.

He came accompanied by his mother. At the beginning of the evaluation, he asked if his mother had to stay in the room; he would rather she left. When asked how he was feeling, he replied: "It's all the same." He said that he does not like to talk a lot and preferred to observe. He had started law school at the beginning of 2012, and he said: "I like criminal and civil law, the rest is boring. It makes me sleepy. Things that do not interest me, I do not care." M was undergoing professional training at a police precinct and described it as "boring"; he used the Internet and provided general information to people about police services. "The schedule is uncomfortable, from 8 am to 2 pm; I have no lunch time, but at least it is paid." $\mathrm{He}$ said that he did not feel the need to go out to have fun or to have a girlfriend. He did not like the town where he lived, but he could not leave the city because his mother would be alone and, furthermore, he was not financially capable of leaving. He said that he memorized things better when he wrote them down.

In the second evaluation, the same neuropsychological tests were administered. The Boston Diagnostic Aphasia Examination (Category/Test - Animals) ${ }^{32}$ and the Letter-Number Sequencing (LNS) test (WAIS-III) ${ }^{26,27}$ were also administered to assess verbal fluency and working memory.

\section{Changes in cognitive profile after 14 months}

Between his first and second neuropsychological evaluations, $\mathrm{M}$ showed a persistent inefficiency in working memory. During the Backward Digit Span Test, M exclaimed, "Oh my! It's impossible!" To determine whether the deficit was present in a different working memory task, the LNS was also administered, but $\mathrm{M}$ showed no deficits. This apparently suggests that the Digit Span Test is more complex than the LNS test, and that is why the Digit Span Test but not the LNS test revealed an impairment. Regarding test complexity, ${ }^{33}$ argues that is possible to reveal deficits in working memory associated with ADHD-predominantly inattentive type if a complex span task is used. In agreement with our observation, Descheemaeker et $\mathrm{al}^{8}$ considers impaired working memory as a possible cognitive problem in adults with NF1.

In the block design test - analysis, synthesis and reproduction of an abstract bidimensional visual stimulus - he is again below the expected, nevertheless, a better score in the task was achieved, compared to the first evaluation. Worst results were achieved in the ability to learn information; short term memory suggests sensibility to stimulus overload, what is expressed in the large difference between digit span forward and RAVLT trial I. ${ }^{30}$ His inhibitory control (Stroop III) was below average, suggesting poor ability in regulating his behavior and difficulty in suppressing one piece of information in favor of another. The FAS test showed a slight inefficiency in his organization of cognitive strategies involving search in a phonetic verbal expression. During the second evaluation, the Category Fluency Test (animals) was introduced to assess semantic verbal expression, and his result was above average. M's performance improved on tasks requiring the simultaneous processing of multiple visual stimuli (Stroop II), and he did not show difficulties in mental flexibility (TMT part B). His sustained attention (CPT test) and verbal memory abilities (RAVLT) were preserved between evaluations.

In summary, after 14 months, $\mathrm{M}$ showed a decline in verbal learning, visual memory, and problem solving. His cognitive strengths were related to sustained attention, verbal memory, and semantic ability, and his cognitive weaknesses were related to visuospatial function (ROCF), phonetic language (FAS), reasoning, and concept formation (WCST).

M's poor performance in visuospatial tasks suggests cognitive dysfunction specifically related to NF1. We also observed impairments in tests that depend on reaction time (selective attention and inhibitory control). Greater demands on cognition may result in poorer inhibitory control in adolescents with NF $1 .^{34}$ On the other hand, M also presents neuropsychological characteristics of patients with ADHD, especially the inattentive subtype. These patients may show satisfactory performance that is not representative of their executive function, which may explain fluctuations in the results of their evaluations. ${ }^{33}$

We observed fluctuations in his cognitive performance. Impaired performance in attentional tests has been described for both NF1 and ADHD patients, but fluctuations in reaction times have only been observed in ADHD patients. Mautner et $a{ }^{15}$ found variable reaction times in children with NF1 and ADHD but not in children with only NF1.

Across the 14-month follow-up period, M took MPH-IR for only 2 months, and it appeared that his cognitive deficits 
did not improve with the medication. In a previous study, parents of children with NF1 on stimulant medication reported that their children continued to show attention problems in daily life. ${ }^{7}$

Benign or noncancerous tumors known as neurofibromas develop underneath the skin and other parts of the body, particularly in the central and peripheral nervous systems. ${ }^{35}$ The brainstem gliomas that are sometimes associated with NF1 usually develop very slowly and induce symptoms such as vomiting and respiratory changes. ${ }^{36}$ As low-grade brainstem gliomas are usually less aggressive in patients with NF1 than in patients without NF1, their prognosis is usually good, and neurosurgical interventions may not be necessary. ${ }^{37,38} \mathrm{M}$ 's low-grade glioma did not appear to influence his cognitive performance in neuropsychological tests. We found no published reports on the cognitive profile of patients with ADHD, NF1, and low-grade pontine gliomas. M's cognitive performance at baseline and 14 months later was compared with normative data from a large sample of individuals (Table 1).

Table I Results obtained on cognitive variables by the patient at baseline and at I4 months' follow-up

\begin{tabular}{|c|c|c|c|}
\hline & \multicolumn{2}{|c|}{$\begin{array}{l}\text { Achieved measures } \\
\text { Mean }( \pm \text { SD) } \\
\text { Scores* }\end{array}$} & \multirow[t]{2}{*}{$\begin{array}{l}\text { Expected measures } \\
\text { Mean }( \pm \text { SD) } \\
\text { Scores* }\end{array}$} \\
\hline & Baseline & At 14 months & \\
\hline MMSE & 28 & 30 & $27.17( \pm 1.94)$ \\
\hline Stroop I & 16 & 19 & II.79 ( \pm 2.79$)$ \\
\hline Stroop II & 21 & 18 & $13.46( \pm 3.11)$ \\
\hline Stroop III & 20 & 28 & $21.28( \pm 5.37)$ \\
\hline Block design (WAIS-R) & 8 & 8 & 10 \\
\hline Vocabulary (WAIS-R) & 8 & 8 & 10 \\
\hline TMT-A & 48 & 31 & $27.4( \pm 9.6)$ \\
\hline TMT-B & 73 & 49 & $58.7( \pm 15.9)$ \\
\hline ROCF - Copy & 23 & 25 & $32.82( \pm 3.19)$ \\
\hline FAS & 26 & 28 & $44.7( \pm I \mid .2)$ \\
\hline RAVLT I & 5 & 6 & $6.19( \pm 1.62)$ \\
\hline RAVLT II & 9 & 7 & $8.78( \pm 1.91)$ \\
\hline RAVLT III & 10 & 8 & $9.88( \pm I .70)$ \\
\hline RAVLT IV & 12 & 8 & 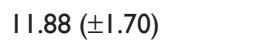 \\
\hline RAVLT V & 14 & 10 & $12.59( \pm 1.62)$ \\
\hline Total RAVLT I to V & 50 & 40 & $49.31( \pm 6.14)$ \\
\hline RAVLT (Interference) & 3 & 3 & $4.47( \pm 1.50)$ \\
\hline RAVLT VI (Immediate recall) & 11 & 9 & $10.84( \pm 1.85)$ \\
\hline RAVLT VII (Delayed recall) 30' & 10 & 10 & $10.34( \pm 2.13)$ \\
\hline ROCF (Delayed recall) 30' & 22 & 7 & $18.70( \pm 6.64)$ \\
\hline WCST (Categories) & 3 & 2 & 4 \\
\hline CPT omissions & 46.88 & 49.76 & $45-54$ \\
\hline CPT commissions & 48.31 & 50.49 & $45-54$ \\
\hline $\mathrm{CPT}$ reaction time & 50.34 & 53.90 & $45-54$ \\
\hline Digit Span Forward/Backward - total (WAIS-III) & 10 & 14 & 10 \\
\hline Digit Span Forward (WAIS-III) & 8 & 13 & Not available \\
\hline Digit Span Backward (WAIS-III) & 5 & 6 & Not available \\
\hline LNS (WAIS-III) & Not applied & 11 & 10 \\
\hline Catergory Test (animals) & Not applied & 26 & I5.88 ( $( \pm 4.25)$ \\
\hline
\end{tabular}

Notes: The patient showed a decline in performance over time in the RAVLT Test; trails IV, V, and total from I to V (learning); ROCF Test (visual delayed recall); Stroop I and III tests (selective attention and inhibitory control); and WCST Task (categories; difficulty in selecting adequate answers in response to demands of the environment). The patient showed improved performance over time in the ROCF copy (visuospatial function) and Stroop II Test (selective attention). The patient showed unchanged performance in the Block Design Test (designed to be a non verbal IQ test), Vocabulary Test (designed to be a verbal IQ test), and FAS Test (phonetic fluency). The patient's cognitive performance ranged from superior average to inferior average in the RAVLT Test; trials II, III, and VI (learning and immediate verbal memory). The patient showed no changes in performance in the RAVLT Test trials I, Interference, and VII (attention span, interference, and verbal delayed recall, respectively), CPT II Test (to assess sustained attention), and Digit Span Test; total number of correct sequences Forward and Backward (working memory). The patient showed better performance in the Forward than in the Backward Digit Span, The Category Test (Animals) assesses semantic fluency and LNS test (working memory) were only administered during the second neuropsychological evaluation.

Abbreviations: CPT, Continuous Performance Test; FAS, one form of the Controlled Oral Word Association Test using the letters F, A, and S; LNS, Letter-Number Sequencing; MMSE, Mini-Mental State Exam; RAVLT, Rey Auditory Verbal Learning Test; ROCF, Rey-Osterrieth Complex Figure Test; TMT, Trail Making Test; WAIS, Wechsler Adult Intelligence Scale; WCST, Wisconsin Card Sorting Test. 


\section{The relationship between NF I and inattention: NF I/ADHD comorbidity or NF I with secondary ADHD-like symptoms?}

The case of M presents a cognitive profile that is related to both NF1 and ADHD. In the follow-up 14 months after the initial evaluation, we observed a mild improvement in some cognitive functions. This improvement might be attributed to intraindividual variability usually observed in ADHD, as the cognitive performance of ADHD patients is often variable depending on the context. Our observations lead us to conclude that $\mathrm{M}$ exhibited comorbid ADHD instead of secondary ADHD-like symptoms.

Some limitations of this case study should be considered. Improved performance with serial neuropsychological testing, even if modest, should be considered with caution because it could reflect a practice effect ${ }^{39}$ instead of genuine improvement of cognitive abilities. According to Duff, ${ }^{40}$ larger practice effects can occur for tests based on fluid abilities. Because M did not report any sleep complaints, we did not perform polysomnography or actigraphy as suggested by Maraña Pérez et $\mathrm{al}^{16}$ to check sleep disorder in patients with NF1. Because the low-grade glioma occurred in a non-cognitive brain area and exhibited slow growth, it probably did not influence M's cognitive performance, although there is a lack of studies of patients with NF1, ADHD, and gliomas. Therefore, our results cannot be generalized to all adults with NF1 and ADHD.

\section{Conclusion}

Neuropsychological testing of M revealed an NF1 profile and some ADHD characteristics. M was more talkative during the second evaluation than during the first one and verbalized his doubts more often, thus demonstrating his cognitive difficulties. M's low average IQ may have partly contributed to some of his deficits, such as difficulties in comprehending instructions, starting activities, planning and conducting a sequence of activities toward a complex goal, and abstraction. Slight inefficiency in organizing his thoughts and difficulties in self-regulation may have affected his responses to the demands of the environment. Some of the results of neuropsychological testing are difficult to interpret, such as M's learning impairments. One explanation for the changes in his behavior between the two evaluations could be because $\mathrm{M}$ began studying and working before the second evaluation; with more cognitive demands, M may have been vulnerable to stimulus overload and fatigue.

This 14-month follow-up case study is complex due to the number of variables arising in association with the core pathology of adults with NF1, ADHD, and pontine low-grade glioma, but it offers an opportunity to begin to understand the relationships among these variables. This case also demonstrates the need for further studies to provide a better understanding of the cognitive characteristics of adults with NF1 who also exhibit attentional deficits or low-grade pontine gliomas.

\section{Disclosure}

The authors report no conflicts of interest in this work.

\section{References}

1. Tonsgard JH. Clinical manifestations and management of neurofibromatosis type 1. Semin Pediatr Neurol. 2006;13(1): 2-7

2. Parisi P, Persechino S, Paolino MC, et al. Four-year follow-up study in a NF1 boy with a focal pontine hamartoma. Ital J Pediatr. 2013;11(39)10: doi: 10.1186/1824-7288-39-10.

3. Carotenuto M, Esposito M. Nutraceuticals safety and efficacy in migraine without aura in a population of children affected by neurofibromatosis type I. Neurol Sci. 2013;34(11):1905-1909.

4. Esposito M, Marotta R, Roccella M, et al. Pediatric neurofibromatosis 1 and parental stress: a multicenter study. Neuropsychiatr Dis Treat. 2014;10:141-146.

5. Hyman SL, Shores A, North KN. The nature and frequency of cognitive deficits in children with neurofibromatosis type 1. Neurology. 2005;65(7):1037-1044.

6. Payne JM, North KN. Neurofibromatosis type 1. In: Goldstein S, Reynolds CR, editors. Handbook of Neurodevelopmental and Genetic Disorders in Children. New York: The Guilford Press; 2011:322-337.

7. Isenberg JC, Templer A, Gao F, Titus JB, Gutmann DH. Attention skills in children with neurofibromatosis type 1. J Child Neurol. 2013;28(1): 45-49.

8. Descheemaeker MJ, Plasschaert E, Frijns JP, Legius E. Neuropsychological profile in adults with neurofibromatosis type 1 compared to a control group. J Intellect Disabil Res. 2013;57(9):874-886.

9. Pavol M, Hiscock M, Massman P, Moore Iii B, Foorman B, Meyers C. Neuropsychological function in adults with von Recklinghausen's neurofibromatosis. Dev Neuropsychol. 2006;29(3):509-526.

10. Ferner RE, Huson SM, Thomas N, et al. Guidelines for the diagnosis and management of individuals with neurofibromatosis 1 . J Med Genet. 2007;44(2):81-88.

11. Garg S, Lehtonen A, Huson SM, et al. Autism and other psychiatric comorbidity in neurofibromatosis type 1: evidence from a populationbased study. Dev Med Child Neurol. 2013;55:139-145.

12. Mautner VF, Granström S, Leark RA. Impact of ADHD in adults with neurofibromatosis type 1: associated psychological and social problems. J Atten Disord. 2015;19(1):35-43.

13. Weiss MD, Weiss JR. A guide to the treatment of adults with ADHD. J Clin Psychiatry. 2004;65 Suppl 3:27-37.

14. Seidman LJ. Neuropsychological functioning in people with ADHD across the lifespan. Clin Psychol Rev. 2006; 26(4): 466-485.

15. Mautner VF, Kluwe L, Thakker SD, Leark RA. Treatment of ADHD in neurofibromatosis type 1. Dev Med Child Neurol. 2002;44:164-170.

16. Maraña Pérez AI, Duat Rodríguez A, Soto Insuga V, Domínguez Carral J, Puertas Martín V, González Gutíerrez Solana L. Prevalence of sleep disorders in patients with neurofibromatosis type 1. Neurologia. Epub 2014 Jun 26. English, Spanish.

17. Licis AK, Vallorani A, Gao F, et al. Prevalence of sleep disturbances in children with neurofibromatosis type 1. J Child Neurol. 2013;28(11):1400-1405.

18. Owens JA, Spirito A, McGuinn M, Nobile C. Sleep habits and sleep disturbance in elementary school-aged children. J Dev Behav Pediatr. 2000;21(1):27-36. 
19. Johnson H, Wiggs L, Stores G, Huson SM. Psychological disturbance and sleep disorders in children with neurofibromatosis type 1. Dev Med Child Neurol. 2005;47(4):237-242.

20. Uttner I, Wahlländer-Danek U, Danek A. [Cognitive impairment in adults with neurofibromatosis type 1]. Fortschr Neurol Psychiatr. 2003;71(3):157-162. German.

21. Shaughnessy JJ, Zechmeister EB, Zechmeister JS. Single-case designs and small-n research. In: Research Methods in Psychology. Part IV: Applied Research. 9th ed. New York: McGraw-Hill; 2012.

22. American Psychiatric Association. Diagnostic and Statistical Manual of Mental Disorders, Fourth Edition, Text Revision. Washington, DC: American Psychiatric Association; 2000.

23. Kaufman J, Birmaher B, Brent D, et al. Schedule for Affective Disorders and Schizophrenia for School Age Children-Present and Lifetime Version (K-SADS-PL): initial reliability and validity data. J Am Acad Child Adolesc Psychiatry. 1997;36:980-988.

24. Mattos P, Segenreich D, Saboya E, Louzã M, Dias G, Romano M Adaptação transcultural para o português da escala Adult Self-Report Scale para avaliação do Transtorno de Déficit de Atenção/Hiperatividade (TDAH) em adultos [Transcultural adaptation of the Adult SelfReport Scale into Portuguese for evaluation of adult attention-deficit/ hyperactivity disorder (ADHD)]. Rev Psiq Clin. 2006;33(4):188-194. Portuguese.

25. Brucki SM, Nitrini R, Caramelli P, Bertolucci PH, Okamoto IH. [Suggestions for utilization of the mini-mental state examination in Brazil]. Arq Neuropsiquiatr. 2003;61(3B):777-781. Portuguese.

26. Nascimento E. WAIS-III - Escala de inteligência Wechsler para adultos. $3^{a}$ Ed. Manual para administração e avaliação/David Wechsler Adaptação e padronização de uma amostra brasileira. WAIS-III. [Wechsler Intelligence Scale for Adults. 3th ed. Administration and Scoring Manual]. São Paulo: Casa do Psicólogo; 2004. Portuguese.

27. Wechsler D. Wechsler Adult Intelligence Scale-Revised. (WAIS-R) New York: Psychological Corporation; 1981.

28. Escala Wechsler de Inteligência para Adultos - Revista (WAIS-R) $e$ sua adaptação para uso no Brasil. [Wechsler Intelligence Scale for Adults Revised (WAIS-R) and its adaptation for use in Brazil] [master thesis]. São Paulo: Pontifícia Universidade Católica (PUC); 1987. Portuguese. Available from: http://consorcio.bn.br/scripts/odwp032k.

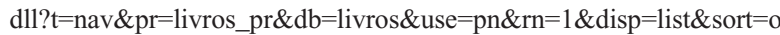
ff\&ss $=59897719 \&$ arg=brandao, \%20elizabeth. Accessed February 10, 2015 .
29. Spreen O, Strauss E. A Compendium of Neuropsychological Tests: Administration, Norms, and Commentary. New York: Oxford University Press; 1998.

30. Lezak MD, Howieson DB, Loring DW. Neuropsychological Assessment. New York: Oxford University Press; 2004.

31. Kayl AE, Moore BD 3rd. Behavioral phenotype of neurofibromatosis, type 1. Ment Retard Dev Disabil Res Rev. 2000;6(2):117-124.

32. Brucki SMD, Malheiros SMF, Okamoto IH, Bertolucci PHF. Dados normativos para o teste de fluência verbal Categoria Animais em nosso meio. [Normative data on the verbal fluency test in the animal category in our milieu]. Arq Neuropsiquiatr. 1997;55(1):56-61. Portuguese.

33. Diamond A. Attention-deficit disorder (attention-deficit/ hyperactivity disorder without hyperactivity): a neurobiologically and behaviorally distinct disorder from attention-deficit/hyperactivity disorder (with hyperactivity). Dev Psychopathol. 2005;17(3):807-825.

34. Rowbotham I, Pit-ten Cate IM, Sonuga-Barke EJ, Huijbregts SC. Cognitive control in adolescents with neurofibromatosis type 1. Neuropsychology. 2009;23(1):50-60.

35. Albers AC, Gutmann DH. Gliomas in patients with neurofibromatosis type 1. Expert Rev Neurother. 2009;9(4):535-539.

36. Grier JT, Batchelor T. Low-grade gliomas in adults. Oncologist. 2006; 11:681-693.

37. Molloy PT, Bilaniuk LT, Vaughan SN, et al. Brainstem tumors in patients with neurofibromatosis type 1: a distinct clinical entity. Neurology. 1995;45:1897-1902.

38. Jett K, Friedman JM. Clinical and genetic aspects of neurofibromatosis 1 . Genet Med. 2010;12(1):1-11.

39. Calamia M, Markon K, Tranel D. Scoring higher the second time around: meta-analyses of practice effects in neuropsychological assessment. Clin Neuropsychol. 2012;26(4):543-570.

40. Duff K. Evidence-based indicators of neuropsychological change in the individual patient: relevant concepts and methods. Arch Clin Neuropsychol. 2012;27(3):248-261.
Neuropsychiatric Disease and Treatment

\section{Publish your work in this journal}

Neuropsychiatric Disease and Treatment is an international, peerreviewed journal of clinical therapeutics and pharmacology focusing on concise rapid reporting of clinical or pre-clinical studies on a range of neuropsychiatric and neurological disorders. This journal is indexed on PubMed Central, the 'PsycINFO' database and CAS,

\section{Dovepress}

and is the official journal of The International Neuropsychiatric Association (INA). The manuscript management system is completely online and includes a very quick and fair peer-review system, which is all easy to use. Visit http://www.dovepress.com/testimonials.php to read real quotes from published authors. 